\title{
The Effectiveness of the Community Movement Program Healthy as Efforts Prevention Syndrome Dyspepsia at UPN Veteran Jakarta of Pandemic Covid 19
}

\author{
Fathinah Ranggauni Hardy ${ }^{1 *}$, Rafiah Maharani Pulungan ${ }^{2}$, \\ Agustina $^{3}$ Erin Kurnia Sari ${ }^{4}$, Reynanda Nadhira Rinaldi ${ }^{5}$ \\ 1,2,3,4,5 Public Health Program, Faculty of Health Sciences, \\ Universitas Pembangunan Nasional Veteran Jakarta Corresponding \\ Author: fathinahranggauni@upnvj.ac.id
}

\begin{abstract}
The incidence of dyspepsia emergency can be caused by various factors of risk, such as age, type of sex, the activity physical, smoke, status of nutrition, environment, social economy, patterns of eating and the frequency breakfast habit in the week, the eating habit of beverage risk such as coffee, tea, soda or risk foods such as food spicy, sweet, sour, and high fat. The pattern of eating that is not regularly on adolescents have a relationship that is meaningful to the onset of dyspepsia as having a value of significance 0.009 and $\mathrm{OR}=6.8354$ (95\% CI: 1.197 to 3.608). Meanwhile, the condition of the university which can affect the Civitas Academica UPN Veteran Jakarta exposed syndrome, dyspepsia are civitas academic is a group of age at risk (age productive), the burden of work and the demands of the job are high and stress, and things are compounded by the style of life that is more risk in the community of academic against the occurrence of dyspepsia syndrome. Syndrome Dyspepsia can be prevented by applying the pattern of movement of people healthy that cover, the pattern of eating that regularly, manage stress, not smoking and drinking alcohol, eating vegetables and fruit as well as detection of early through examination of health. It mentioned the background of the researcher to examine related Effectiveness Society Movement Healthy as Prevention Syndrome Dyspepsia at Civitas Academica UPN Veteran Jakarta during the pandemic Covid 19.
\end{abstract}

Keywords: Syndrome Dyspepsia, Movement, People, Healthy

\section{BACKGROUND}

The incidence of dyspepsia occurs mostly in the adolescent to young adult age group as indicated by the high number of dyspepsia cases at a young age of $38 \%$ [1]. Adolescents are an age group that is more at risk for experiencing dyspepsia symptoms where adolescents are experiencing physical and psychological transfers from children to adults by starting to have a lot of activity to take up time so that it has an impact on irregular eating patterns [2]. The incidence of dyspepsia, especially in adolescents, can have a negative impact on the quality of life which can interfere with their daily activities which tend to be busy [3].

The prevalence of $13 \%$ to $40 \%$ of the total population every year in the world has dyspepsia. Research has found that Europe, the United States and Oceania have a prevalence of dyspepsia ranging from $5 \%$ to $43 \%$ [4]. The prevalence of dyspepsia globally in the world ranges from up to $29.2 \%$ [5]. The results of research in Asian countries such as China, Hong Kong, Indonesia, Korea, Malaysia, Singapore, Taiwan, Thailand and Vietnam found that the prevalence of dyspepsia ranged from $43 \%$ to $79.5 \%$ [6].

Dyspepsia was ranked 10th in the most disease classifications according to the 2007 Indonesian Health Profile data in patients with the category of hospitalized inpatients in 2006 with 34,029 patients or about $1.59 \%$ [7]. This incidence rate has increased from 2006 to 2009 to 47,304 cases which are in the fifth order of the top 10 in the most disease group in hospital in inpatients in 2009, while in hospital patients who undergo outpatient treatment the number of dyspepsia cases accounts for the number of cases the bigger one with 133,162 cases [8].

Based on the Health Profile of Depok City in 2017 , dyspepsia ranks the second highest case of noncommunicable diseases with 77,403 cases. The incidence of dyspepsia in 2017 , it was included in the top 10 most diseases in patients with road care at the puskesmas in Depok City which was in fourth place 
with a prevalence of $8.04 \%$ or 76,069 cases [9]. Based on the list of outpatient diseases at the Puskesmas according to the age group 15-44 years, where this age group includes adolescents in Depok City, 2017 shows dyspepsia is included in the top five diseases which ranks fourth with a prevalence of $10.31 \%$ or 47,315 cases [9].

The emergence of dyspepsia may be caused by various risk factors, such as age, gender, exercise habits or physical activity, smoking, nutritional status, environment, socioeconomic, diet which includes regularity, frequency and interval of eating, eating breakfast habits. frequency during the week, the habit of consuming risky drinks (coffee, tea, soda), and the habit of consuming risky foods (spicy, sweet, sour, and high-fat foods). An unregulated diet in adolescents has a significant relationship with the onset of dyspepsia because it has a significance value of 0.009 and $\mathrm{OR}=$ 6.8354 (95\% CI: 1.197-3.608) meaning that adolescents with irregular eating patterns have 6.8354 times the risk more likely to experiencedyspepsia than adolescents who eat regularly [10].

Research shows adolescents who have a habit of consuming spicy food every day have 3,730 times greater risk of experiencing dyspepsia than those who do not have the habit of consuming spicy food every day with OR $=3,730$ (95\% CI: 2,098-6,630) [11]. The study found that if you have a long meal break will cause dyspepsia by 3.027 times a greater risk than those who have a good interval between eating with OR = 3.027 (95\% CI: 1.484-6,172) [11].

Meanwhile, the condition of the university that can affect the UPN Veteran Jakarta Academic Community affected by the dyspepsia syndrome is that the academic community is a risky age group (productive age), high workload and job demands and stress, and this is exacerbated by a more risky lifestyle for the academic community. against the occurrence of dyspepsia syndrome. Dyspepsia syndrome can be prevented by implementing a healthy community movement pattern which includes, regular eating patterns, managing stress, not smoking and drinking alcohol, eating vegetables and fruits and early detection through medical examination. This is the background for researchers to research related to the Effectiveness of the Healthy Community Movement as Dyspepsia Syndrome Prevention in the Academic Community of UPN Veteran Jakarta.

\section{METHOD}

This research uses quantitative analytic research design with cross sectional study design, which is a study design that studies the relationship between the studied risk factors or exposure with predetermined events or outcomes. Cross sectional study is a study that was conducted at the same time [12]. The factors that will be examined are divided into two groups of variables, namely the dependent variable and the independent variable. In addition, there are other variables that affect dyspepsia, namely age, gender, and exercise habits. The dependent variable is dipepsia, while the independent variable is diet which includes the frequency and interval of eating, breakfast habits, the habit of consuming risky foods and the habit of consuming risky drinks, work stress and the effectiveness of healthy community movements. Many other related variables can cause dyspepsia that have existed in other theories and studies, but in this study only a few variables were taken because of the limitations of the study.

Research place at UPN Veteran Jakarta.

Research time is from February to June 2020. Population is a generalization area consisting of objects (objects) or subjects (people) that have certain qualities and characteristics which are then determined by the researcher to be examined and conclusions are drawn [13]. The population in this study was the entire academic community of the Veteran National Development University Jakarta.

The sampling technique in this study consisted of 2 sampling techniques, the first technique used stratified random sampling or Proportionate Stratified Random Sampling to determine the stratification of the academic community. Proportionate Stratified Random Sampling is used when a population has different characteristics [14]. In this study, the strata in question is based on the characteristics of the academic community consisting of lecturers, education staff, and students. After determining the stratification, a purposive sampling technique was carried out to obtain a suitable sample for this study. Based on preliminary studies that have been carried out at the General and Finance Bureau and Academic, Student, Planning and Cooperation Bureau (AKPK), the total population of the UPN Veteran Jakarta Academic Community is 11,456, each consisting of 441 lecturers; 398 education staff; and

10,671 students. To find out the number of samples needed in this study, the researcher used the Slovin formula because the population was already known: After calculating using the Slovin formula, the minimum number of samples in this study was $n=387$. With each sample based on the stratification formula.

\section{RESULTS}

Univariate analysis is used to explain and describe the frequency distribution of the dependent variable and the independent variable. The dependent variable in this study was Dyspepsia Syndrome in the UPN Veteran Jakarta academic community, while the independent variables in this study were age, gender, smoking, consumption of risky drinks, eating frequency, consumption of spicy foods, consumption of sour foods, coffee consumption, and stress. The prevalence of dyspepsia for the period March - April 2020 in this study, are as follows: 
Table 1 Overview of Dyspepsia Prevalence in UPN Veteran Jakarta

\begin{tabular}{|l|c|c|}
\hline Syndrom Dyspepsia & $\mathbf{n}$ & Percentage (\%) \\
\hline Dyspepsia Syndrome & 141 & 35,3 \\
\hline Not Dyspepsia Syndrome & 259 & 64,7 \\
\hline Total & 400 & 100 \\
\hline
\end{tabular}

Table 2 Description of Dyspepsia Symptoms Experienced by the Academic Community of UPN Veteran Jakarta

\begin{tabular}{|l|c|c|}
\hline Syndrom Dyspepsia & $\mathbf{n}$ & Percentage (\%) \\
\hline Left Abdominal Pain & 116 & 29,0 \\
\hline Nausea & 116 & 29,0 \\
\hline Vomiting & 28 & 7,0 \\
\hline Bloating & 110 & 27,5 \\
\hline Stomach Pain Feels Burning & 71 & 17,8 \\
\hline Heartburn & 128 & 32,0 \\
\hline
\end{tabular}

Table 3 Bivariate Analvsis of Modifiable Risk Factors with DvspepsiaSvndrome

No Variabel

Dyspepsia Syndrome

Experienced Not Experienced P Value

OR

$\mathbf{9 5 \%}$

\begin{tabular}{|c|c|c|c|c|c|c|c|c|c|}
\hline & & $\mathbf{n}$ & $\%$ & $\mathbf{n}$ & $\%$ & $\mathbf{N}$ & $\%$ & & CI) \\
\hline \multirow[t]{4}{*}{1} & Smoking & & & & & & & & \\
\hline & Smoking & 14 & 25,5 & 41 & 74,5 & 55 & 100 & 0,137 & 0,586 \\
\hline & Not Smoking & 127 & 36,8 & 218 & 63,2 & 345 & 100 & & $(0,308-$ \\
\hline & & & & & & & & & $1,117)$ \\
\hline \multirow[t]{4}{*}{2} & Risky Drinks & & & & & & & & \\
\hline & It's risky & 18 & 46,2 & 21 & 53,8 & 39 & 100 & 0,186 & 1,659 \\
\hline & No Risk & 123 & 34,1 & 238 & 65,9 & 361 & 100 & & $(0,852-$ \\
\hline & & & & & & & & & $3,229)$ \\
\hline \multirow[t]{5}{*}{3} & Eating & & & & & & & & \\
\hline & Frequency & & & & & & & & \\
\hline & $\mathrm{Bad}$ & 90 & 43,3 & 118 & 56,7 & 208 & 100 & 0,001 & 2,109 \\
\hline & Well & 51 & 26,6 & 141 & 73,4 & 192 & 100 & & $(1,383-$ \\
\hline & & & & & & & & & $32,15)$ \\
\hline \multirow[t]{4}{*}{4} & Spicy food & & & & & & & & \\
\hline & It's risky & 87 & 41,0 & 125 & 59,0 & 212 & 100 & 0,014 & 1,727 \\
\hline & No Risk & 54 & 28,7 & 134 & 71,3 & 188 & 100 & & $(1,137-$ \\
\hline & & & & & & & & & $2,623)$ \\
\hline \multirow[t]{5}{*}{5} & Sour Foods & & & & & & & & \\
\hline & It's risky & 11 & 50,0 & 11 & 50,0 & 22 & 100 & & 1,908 \\
\hline & & & & & & & & 0,208 & $(0,805-$ \\
\hline & & & & & & & & & $4,518)$ \\
\hline & No Risk & 130 & 34,4 & 248 & 65,6 & 378 & 100 & & \\
\hline \multirow[t]{6}{*}{6} & Consumption of & & & & & & & & \\
\hline & Coffee & & & & & & & & \\
\hline & It's risky & 4 & 22,2 & 14 & 77,8 & 18 & 100 & & 0,511 \\
\hline & & & & & & & & 0,352 & $(0,165-$ \\
\hline & & & & & & & & & $1,583)$ \\
\hline & No Risk & 137 & 35,9 & 245 & 64,1 & 381 & 100 & & \\
\hline \multirow[t]{5}{*}{7} & Stress Conditions & & & & & & & & \\
\hline & Yes & 105 & 45,1 & 128 & 54,9 & 233 & 100 & & 2.985 \\
\hline & & & & & & & & 0,001 & $(1,903-$ \\
\hline & & & & & & & & & $4,682)$ \\
\hline & Not & 36 & 21,6 & 131 & 78,4 & 167 & 100 & & \\
\hline
\end{tabular}

Sour Foods

The results of the frequency distribution in the UPN Veteran Jakarta academic community, the majority of respondents did not experience Dyspepsia Syndrome $(64.8 \%)$. Based on Table 2, the majority of respondents who experienced dyspepsia experienced symptoms of heartburn $(32 \%)$ and symptoms that were rarely experienced were vomiting $(7.0 \%)$. The description of the frequency distribution of respondents is divided based on non-modifiable risk factors (age and gender) and modifiable risk factors (smoking, consumption of risky drinks, eating frequency, consumption of spicy foods, consumption of sour foods, coffee consumption and stressful conditions. 
In table 3 , it can be seen that respondents who smoke and do not experience Dyspepsia Syndrome (74.5\%). The results of statistical tests obtained $p=0.137$, it can be concluded that $\mathrm{p}>0.05$ means that there is no relationship between smoking and Dyspepsia Syndrome. Respondents who smoke have a tendency of 0.586 times to experience Dyspepsia Syndrome compared to respondents who do not smoke $(95 \% \mathrm{CI}$ : 0308-1,117).

Based on table 3 , respondents who have a habit of consuming risky drinks and do not experience Dyspepsia Syndrome (53.8\%). The statistical test results obtained $\mathrm{p}=0.186$, meaning that $\mathrm{p}>0.05$, there is no relationship between the habit of consuming risky drinks and Dyspepsia Syndrome. Respondents who have a habit of consuming risky drinks have a tendency of 1.659 times to experience dyspepsia syndrome (95\% CI: $0.852-3.229$ ). In table 3, it can be seen that respondents who had a large eating frequency $<3$ times a day (frequency of bad eating) and experienced dyspepsia syndrome $(43.3 \%)$. The results of statistical tests obtained $\mathrm{p}=0.001$, it can be concluded that $\mathrm{p}$ $<0.05$ means that there is a relationship between eating frequency and Dyspepsia Syndrome. Respondents who ate $<3$ times a day had a tendency of 2.109 times to experience dyspepsia syndrome (95\% CI: $1.383-$ 32.15).

Based on table 3 Respondents who have a habit of consuming spicy food (at risk) and do not experience Dyspepsia Syndrome (59\%). The statistical test results obtained $\mathrm{p}=0.014$, meaning $\mathrm{p}<0.05$, and it can be concluded that there is a relationship between consumption of spicy food and Dyspepsia Syndrome. Respondents who eat spicy food have a tendency to develop 1,727 times Dyspepsia Syndrome (95\% CI: $1,137-2,623$ ).

Based on table 3, the proportion of respondents who consumed acidic foods in the group with dyspepsia syndrome and the group without dyspepsia syndrome was the same (50\%). The statistical test results obtained $p=0.208$, meaning $p$ > 0.05 and it can be concluded that there is no relationship between consumption of sour foods and Dyspepsia Syndrome. Respondents who ate acidic foods had a tendency of 1.908 times to experience dyspepsia syndrome (95\% CI: 0.805-4.518).

In table 3 respondents who have a habit of consuming coffee (at risk) and do not experience dyspepsia syndrome $(77.8 \%)$. The statistical test results obtained were 0.352 , meaning $p>0.05$, it can be concluded that there is no relationship between coffee consumption habits and Dyspepsia Syndrome. Respondents who have a habit of consuming coffee have a tendency of 0.511 times to experience dyspepsia syndrome (95\% CI: $0.165-1.583$ ). Based on table 3, respondents who experienced stress and did not experience dyspepsia syndrome (54.9\%). The statistical test results obtained $p=0.001$, meaning that $p<0.05$, it can be concluded that there is a relationship between stress and Dyspepsia Syndrome. Respondents who experienced stress had a tendency of 2,985 times to develop dyspepsia syndrome (95\% CI: 1,9034,683).

\section{DISCUSSION}

The results of the analysis in this study indicate that stress conditions have a relationship with dyspepsia syndrome. Respondents with stress conditions were 2.86 times more likely to experience dyspepsia syndrome than those without stress. This is in line with research conducted by [15] with $\mathrm{p}$ value $=$ $0.001<0.05(95 \% \mathrm{CI})$, which means that there is a significant relationship between stress and the incidence of gastritis. In research conducted by [15], it is stated that respondents with a stressful state tend 27.3 times to experience gastritis compared to those without stress.

Stress has a negative effect through the neuroendocrine mechanism on the digestive tract so that you are at risk for experiencing gastritis. In stressful situations, stomach acid production will increase, for example when you are in a panic and in a hurry or when your workload increases. Increased levels of stomach acid can irritate the gastric mucosa and if left untreated it can cause gastritis [16][17].

In this study, data collection was carried out in September-December 2019 where, during that time period, the academic community had higher job demands compared to the previous month. This was proven because at the time of the research, educational staff were required to close the fiscal year deadlines, lecturers with journal deadlines and other assignments and students with deadlines for assignments and Final Semester Examinations (UAS) so that the majority of respondents in this study were experiencing stress.

The results of multivariate analysis showed that the frequency of eating was statistically related to dyspepsia syndrome. Respondents with a meal frequency $<3$ times a day tended to experience 1,983 times the dyspepsia syndrome compared to respondents with a meal frequency $\geq 3$ times a day. The results of this study are in line with research conducted by [18] which states that there is a relationship between the frequency of bad eating and the incidence of gastritis $\mathrm{p}=0.004$ $<0.05$ (95\% CI: 1.536 - 7.448). In a study conducted by [18], it was stated that respondents with a bad frequency of eating were 3,383 times more likely to experience gastritis compared to respondents who had a good frequency of eating.

According to [19] the stomach will naturally continue to produce stomach acid in small amounts every time, after 4-6 hours after eating, usually the glucose level in the blood has been absorbed and used up so that the body will feel hungry, at that time the amount of stomach acid will be stimulated. If a person eats 2-3 hours late from the hour of eating, the more and more stomach acid is produced. As a result, stomach acid will irritate the mucosa in the stomach and cause pain in the epigastrum. The condition of the university that can affect the UPN Veteran Academic Community has a bad eating frequency, namely the workload and high job demands so that the academic community sets aside their rest hours to eat and prefers to finish their work first. 


\section{CONCLUSIONS}

Based on analysis, the most influencing factors with dyspepsia syndrome in the UPN Veteran Jakarta Academic Community are the frequency of eating and stress conditions. The UPN Veteran Jakarta academic community with a poor frequency of eating or $<3$ times a day, and who are experiencing stress have a 2,007 times risk of developing gastritis complaints compared to those who eat well and do not experience stress. Based on the conclusions that have been described, the suggestions that can be given in this research are as follows. Maintain a healthy lifestyle and good diet to reduce the risk of dyspepsia syndrome. Such as the frequency of eating regularly $\geq 3 \mathrm{x}$ a day and reducing to consuming excess spicy foods. Also, good stress management is like doing positive activities or a favorite hobby. With this research, it is hoped that it can become evidence based for institutions in making policies regarding the prevention and control of gastritis in the UPN Veteran Jakarta Campus environment, such as setting appropriate rest hours and implementing healthy canteens. It is hoped that further research can use a study design other than cross- sectional, in order to know a clear causal relationship and use a randomized sampling technique so that the resulting sample can truly represent the population.

\section{ACKNOWLEDGMENT}

Universitas Pembangunan Nasional Veteran Jakarta

\section{REFERENCES}

1. Reshetnikov OV, dkk. (2001). 'Prevalence of dyspepsia and irritable bowel syndrome among adolescent of novosibrik, Instititute of Internal Medicine Russia'. Int. J Circumpolar Health. 60 (2): 253-257.

2. Djojoningrat, D. (2009). Functional Dyspepsia Textbook of Internal Medicine. Volume I. Jakarta: Faculty of Medicine, University of Indonesia. 529531

3. Putri, Nanda Rizki, dkk. (2015). 'Description of Functional Dyspepsia Syndrome in 2014 Students of the Faculty of Medicine, University of Riau'. JOM FK. 2 (2).

4. WHO. (2010). Growth Refrence Data for 5-19 Years. http://www.who.int/growthref/ [diakses 10 November 2019].

5. Mahadeva, S. \& Goh, LK. (2006). 'Epidemiology of Functional Dyspepsia: A Global Perspective'. World Journal of Gastroenterology. Vol. 12, No. 17: 2661-2666.

6. Miwa, H, Ghoshal, UC, Gonlachanvit, S, et al. (2012). 'Asian Consensus Report on Functional Dyspepsia’. J Neurogastroenterol Motil. Vol. 18.

7. Ministry of Health RI (2007) Indonesia Health Data Profile 2008. Jakarta.

8. Ministry of Health RI (2010) Indonesia Health Data Profile 2009. Jakarta.

9. Depok City Health Office (2018) Depok City Health Data Profile 2017. Depok

10. Sorongan Milly Inri, dkk. (2013). 'The Relationship Between Diet and the Incidence of Dyspepsia Syndrome in Class XI Students at SMA Negeri 1' Manado'. eJurnal Nursing. 1 (1).
11. Rosalina M. (2018). 'Factors Associated with Dyspepsia in High School Adolescents in Bogor'. Faculty of Human Ecology, Thesis of Bogor Agricultural University. Bogor: Bogor Agricultural Institute.

12. Notoatmodjo, S. (2012) Health Research Methodology Jakarta: PT Rineka Cipta.

13. Sulistyaningsih (2012) Quantitative - Qualitative Midwifery Research Methodology. First edition. Yogyakarta: Garaha Ilmu.

14. Notoatmodjo, S. (2018) Health Research Methodology. Jakarta: PT Rineka Cipta.

15. Novitasary, A., sabilu, yusuf dan Ismail, C. S. (2017) 'Determinant Factors of Clinical Gastritis in Students at the Faculty of Public Health, Halu Oleo University in 2016', Unsyiah Public Health Student Scientific Journal, 2(6), pp. 1-11.

16. Handayani, S. D., Kokasih, C. E. and Priambodo, A. (2012) "The Relationship between Family Support and Recurrence of Gastritis Patients at Jatinangor Health Center", Padjadjaran Nursing Journal, pp. 1-15.

17. Hungan, W., Supit, D. and Kabo, D. R. (2016) 'The Relationship between Diet and Stress and Gastritis Incidence in Patients Who Go to Puskesmas Remboken', Journal of Nursing, 6 (1), p. 56. doi: https://doi.org/10.3929/ethz-b-000238666.

18. Hartati, S., Utoma, W. and Jumaini (2014) "The Relationship between Diet and Gastritis Risk in Students Under the CBC".

19. Dwigint, S. (2015) 'the Relation of Diet Pattern to Dyspepsia Syndrome', Journal of Majority, 4, pp. 73-80. 